Оригинальная статья/Original article

УДК 66-922.2

DOI: http://doi.org/10.20914/2310-1202-2016-2-218-222

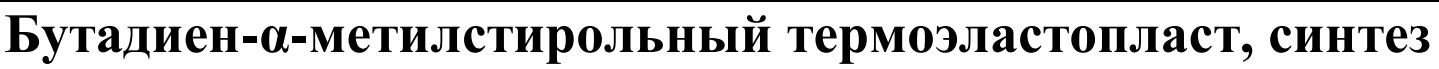 и свойства
}

\begin{abstract}
\begin{tabular}{lll}
\hline \hline Алена В. Фирсова, & 1 & vammp.004@mail.ru \\
Ольга В. Карманова, & 1 & karolga@mail.ru \\
Валентина В. Ситникова, & 2 & vfniisk2007@yandex.ru \\
Евгений В. Блинов & 2 & vfniisk2007@yandex.ru \\
\hline
\end{tabular}
$\overline{1}$ кафедра химии и химической технологии органических соединений и переработки полимеров, Воронеж, гос. ун-т. инж. техн., Ленинский пр-т, 14, г. Воронеж, Россия

${ }^{2}$ Воронежский филиал НИИСК, ул. Менделеева, 3Б, г. Воронеж, 394014, Россия

Реферат. В ряду диен-винилароматических блок-сополимеров особое место занимает бутадиен- $\alpha$-метилстирольный блок - сополимер термоэластопласт (ТЭП ДМСТ-Р), содержащий в качестве пластичного-поли- $\alpha$-метилстирольный блок и эластичного-полибутадиеновый блок. ТЭП ДМСТ-Р отличается повышенной теплостойкостью, эластичностью, сопротивлением износу по сравнению с бутадиенстирольными термоэластопластами (ТЭП ДСТ). Проведён синтез блок-сополимеров бутадиена и $\alpha$-метилстирола, который имеет ряд особенностей по сравнению с синтезом на основе бутадиена и стирола, что связано с поведением $\alpha$-метилстирола в анионной полимеризации высокая скорость полимеризации в полярных средах и низкая скорость реакции в углеводородных растворителях. Технологические сложности при выпуске ДМСТ-Р обусловлены неполной конверсией $\alpha$-метилстирола и необходимостью поддерживать высокую концентрацию от 60 до $80 \%$ a-метилстирола в шихте при синтезе 1-го блока под влиянием анионного катализатора н-бутиллития (н-BuLi). Установлено, что большое значение имеет низкая предельная температура полимеризации $\alpha$ метилстирола $\left(+61^{\circ} \mathrm{C}\right)$ и связанная с этим обратимость реакции и высокая концентрация остаточного мономера. Выявлено, что высокой скорости полимеризации $\alpha$-метилстирола можно достичь проведением реакции в углеводородном растворителе с добавками полярных соединений, таких как тетрагидрофуран (ТГФ) и метилтретбутиловый эфира (МТБЭ). Изучены условия синтеза ДМСТ-Р. Представлена кинетика полимеризации для первого блока ДМСТ-Р. Проведён анализ физико-механических показателей образцов ДМСТ-Р. Оптимальное содержание связанного $\alpha$-метилстирола обеспечивает блок-сополимеру хороший комплекс свойств в сравнительно широком температурном интервале. При увеличении содержания связанного $\alpha$-метилстирола повышается прочность при разрыве при нормальной и повышенной температуре, твёрдость и жёсткость полимера; снижается относительное удлинение и эластичность.

Ключевые слова: термоэластопласт, $\alpha$-метилстирол, н-бутиллитий, тетрагидрофуран, метилтретбутиловый эфир, тетраэтоксисилан, циклогексан, показатель текучести расплава
\end{abstract}

\section{Synthesis and properties of butadiene-alpha-methylstyrene thermoplastic} elastomer

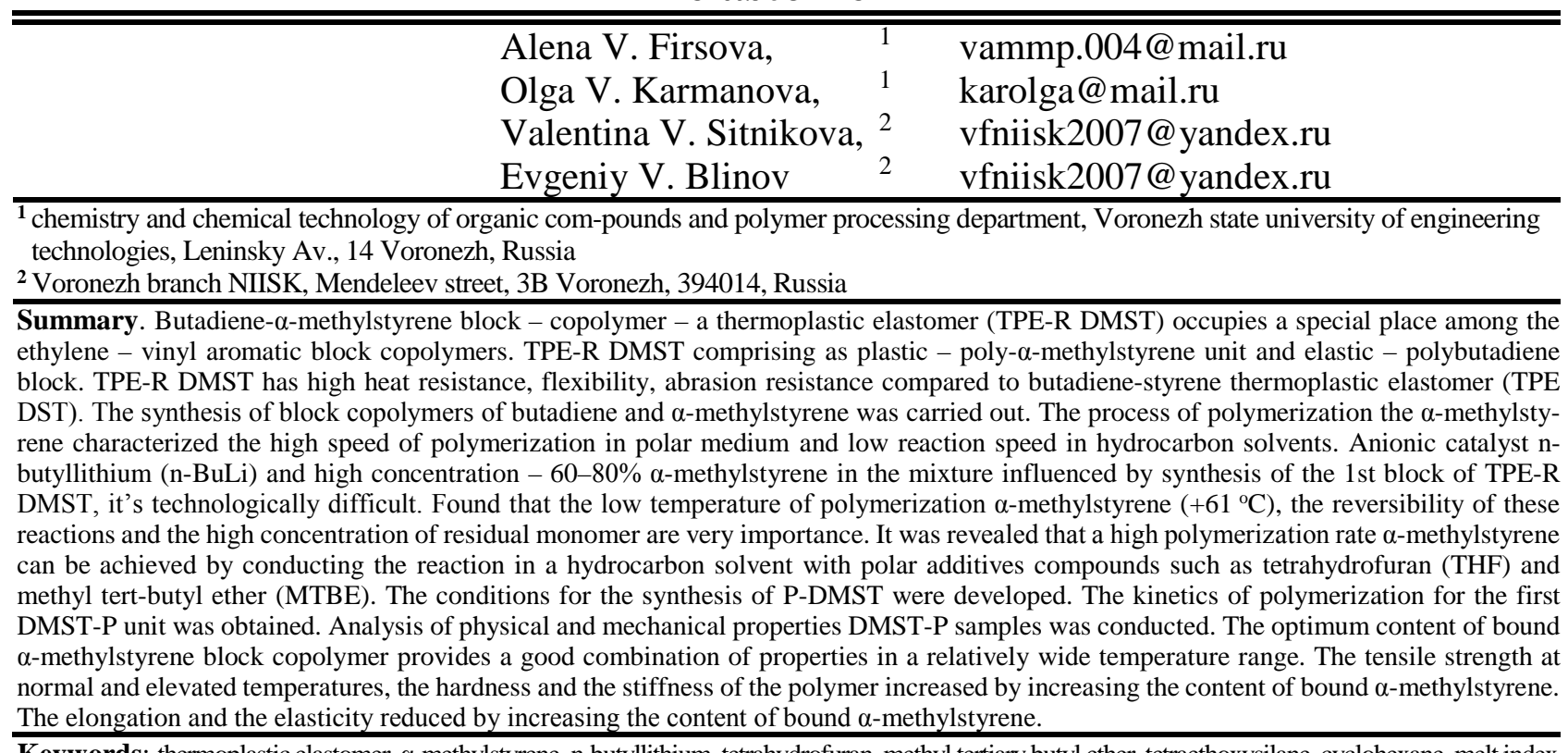
Keywords: thermoplastic elastomer, $\alpha$-methylstyrene, n-butyllithium, tetrahydrofuran, methyl tertiary butyl ether, tetraethoxysilane, cyclohexane, melt index

Для цитирования

Фирсова А. В.,. Карманова О. В, Ситникова В. В., Блинов Е. В. Бутадиен- $\alpha$-метилстирольный термоэластопласт, синтез и свойства // Вестник ВГУИТ. 2016. № 2. С 218-222. doi:10.20914/2310-12022016-2-218-222
For citation

Firsova A. V., Karmanova O. V., Sitnikova V. V., Blinov E. V. Synthesis and properties of butadiene-alpha-methylstyrene thermoplastic elastomer. Vestnik VSUET [Proceedings of VSUET]. 2016. no 2 pp. 218-222 (in Russ.). doi:10.20914/2310-1202-2016-2-218-222 


\section{Введение}

В настоящее время, получение полимерной теплостойкой электроизоляционной композиции с высокими значениями показателей электрической прочности, удельного объёмного сопротивления и дугостойкости, а также имеющей высокие значения физикомеханических показателей условной прочности и относительного удлинения при разрыве является главной задачей.

Перспективным направлением в области синтеза диенвинил-ароматических термоэластопластов (ТЭП) является использование поли- $\alpha$-метилстирола для получения пластичных блоков. Вследствие высокой температуры стеклования поли- $\alpha$-метилстирола $\left(173^{\circ} \mathrm{C}\right)$ термоэластопласты на основе бутадиена и $\alpha$-метилстирола выгодно отличаются от термоэластопластов с полистирольными блоками более широким температурным интервалом сохраняя прочностные и эластические свойства материалов. Оптимальное содержание связанного $\alpha$-метилстирола, обеспечивает хороший комплекс свойств ТЭП ДМСТ-Р и эффективное его использование в составах дорожного битума. При увеличении содержания связанного $\alpha$-метилстирола повышаются прочность при растяжении в условиях комнатной и повышенной температур, твёрдость, жёсткость и остаточное удлинение полимера, снижаются относительное удлинение и эластичность.

Однако при выпуске ДМСТ-Р имеются некоторые технологические сложности, связанные с неполной конверсией $\alpha$-метилстирола и необходимостью поддерживать высокую концентрацию $\alpha$-метилстирола на стадии синтеза 1-го блока. Достаточно высокая скорость полимеризации $\alpha$-метилстирола может достигаться путём проведения реакции в углеводородном растворителе при повышенной концентрации мономера или полимеризацией с добавками полярных соединений, например, таких как тетрагидрофуран.

\section{1 Условия проведения синтеза}

Синтез ТЭП ДМСТ-Р проводился в опытном цехе по двухаппаратной схеме. Синтез 1-го поли- $\alpha$-метилстирольного блока проводился в аппарате ёмкостью 0,2 м³ 2-го блока (полимеризация бутадиена) и «сшивку» двублочного «живущего» сополимера - в аппарате объёмом 2 м $^{3}$.

В полимеризатор ёмкостью $0,2 \mathrm{~m}^{3}$, снабжённый мешалкой якорного типа, циркуляционным насосом, рубашкой для теплоносителя, загружался из дозеров растворитель, $\alpha$-метилстирол, затем подавался ТГФ из переносного контейнера и раствор н-BuLi из дозера на титрование шихты до ярко-вишнёвого цвета. Затем дозировалось расчётное количество н-BuLi на полимеризацию. Температура реакционной массы поддерживается на уровне $18-22{ }^{\circ} \mathrm{C}$ путём подачи хладагента в термостатирующую рубашку аппарата. Полимеризация $\alpha$-метилстирола протекала в течение 3-4-х часов до конверсии $\alpha$-метилстирола 70-72\%.

После достижения заданной конверсии $\alpha$-метилстирола раствор 1-го блока переводился во второй аппарат ёмкостью $2 \mathrm{~m}^{3}$ с предварительно приготовленной бутадиеновой шихтой с концентрацией 16-18\%. Начальная температура реакционной массы в аппарате составляла $10-12{ }^{\circ} \mathrm{C}$. После подачи 1-го блока реакционная масса нагревалась до температуры $25-29^{\circ} \mathrm{C}$, далее полимеризация бутадиена протекала в адиабатическом режиме с повышением температуры до 70-85 ${ }^{\circ} \mathrm{C}$ в течение 20-40 минут. Через 5-7 минут после достижения максимальной температуры в аппарат из переносного контейнера дозировалось расчётное количество сшивающего агента ТЭОС. Реакция «сшивки» протекала в течение 60-90 минут при температуре $60-70{ }^{\circ} \mathrm{C}$.

После завершения синтеза ДМСТ-Р в полимеризат вводилось расчётное количество стабилизатора агидола-2. Заправленный полимеризат подавался в водный дегазатор производительностью 15 кг/час. С целью получения неслипающейся крошки с размером частиц 3-5 мм в дегазатор каждые 15 мин дозировался антиагломератор - хлористый кальций 0,5 л 10\%-го раствора. Сушка - в конвейерной сушилке при температуре $\approx 100{ }^{\circ} \mathrm{C}$.

$\mathrm{B}$ качестве инициирующей системы использовался комплекс н-BuLi - ТГФ, который применяется в промышленном производстве ТЭП. Мольное соотношение ТГФ: н-BuLi $=1-2: 1$.

Для получения разветвлённого ТЭП ДМСТ-Р был выбран четырехфункциональный сочетающий агент тетраэтоксисилан (ТЭОС), широко применявшийся в опытном производстве ТЭП В. ф. НИИСК.

Синтез ТЭП производился в среде углеводородного растворителя - циклоалифатическом (циклогексан) или в смеси с алифатическим (гексан, нефрас). В настоящей работе растворитель содержал более $70 \%$ циклогексана, что обеспечивало хорошую растворимость поли- $\alpha$-метилстирольного блока при высокой концентрации шихты (>60\%) 1-го блока. 
С целью достижения максимально возможной ( $70-75 \%)$ конверсии $\alpha$-метилстирола (при синтезе 1-го блока) необходимо обеспечить, по крайней мере, два условия:

- концентрация $\alpha$-метилстирола в растворителе более $60 \%$ (оптимально $65-75 \%$ );

- температура полимеризации не выше $25{ }^{\circ} \mathrm{C}$ (оптимально $16-22^{\circ} \mathrm{C}$ ).

На рис. 1 представлена кинетика полимеризации І-го поли - $\alpha$-метилстирольного блока с мольными соотношениями ТГФ: $\mathrm{H}-\mathrm{BuLi}=1,58-1,71$.

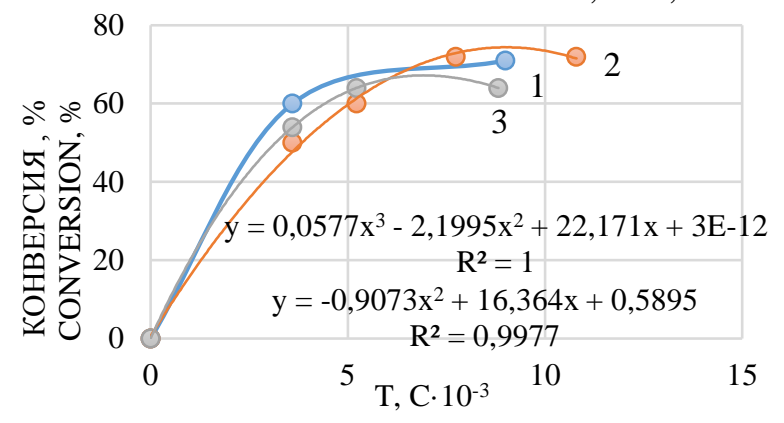

Рисунок 1. Зависимость конверсии $\alpha$-метилстирола от времени полимеризации при соотношении ТГФ/ н-BuLi: 1 - 1,58; 2 - 1,71; 3 - 1,63

Figure 1. The determination of conversion alpha-methylstyrene by the time of polymerization in a ratio of THF/n-BuLi: 1 - 1,58; 2 - 1,71; 3 - 1,63
После завершения полимеризации бутадиена в реакционную массу вводился при температуре $67-78{ }^{\circ} \mathrm{C}$ сшивающий агент - раствор ТЭОС из расчёта эквивалентное соотношение ТЭОС: н-BuLi (общий расход) $=(0,9-1,2): 1,0$.

С целью повышения эффективности «сшивки» подачу ТЭОС осуществляли в два приёма, увеличив общее время «сшивки» до 2-2,5 час. Основное количество ТЭОС дозировалось на 1-й приём, на 2-й приём сверх стехиометрии, чтобы гарантировать достаточное количество функциональных групп для «сшивки».

Физико-механические показатели ДМСТ-Р контролировались в каждом опыте.

Пробы полимеризата отбирались из аппарата на различных стадиях синтеза, заправлялись агидолом-2 ( $1 \%)$ и выделялись на лабораторном водном дегазаторе. «Сшивку» проб осуществляли на вальцах при температуре $80-90{ }^{\circ} \mathrm{C}$.

\section{2 Результаты исследований}

В таблице 1 приведены результаты физико-механических испытаний проб ДМСТ-Р.

Физико-механические свойства образцов ДМСТ-Р

Таблица 1

The physico-mechanical properties of the DMST samples

Table 1.

\begin{tabular}{|c|c|c|c|c|c|c|c|c|c|}
\hline $\begin{array}{c}\text { Наименование показателей } \\
\text { Name of indicators }\end{array}$ & \multicolumn{9}{|c|}{$\begin{array}{l}\text { Значение показателей } \\
\text { Value indicators }\end{array}$} \\
\hline $\begin{array}{c}\text { № опыта } \\
\text { experience number }\end{array}$ & 4 & \multicolumn{2}{|c|}{5} & 6 & \multicolumn{2}{|l|}{7} & \multicolumn{3}{|c|}{9} \\
\hline $\begin{array}{c}\text { «сшивка» } \\
\text { "crosslinking" }\end{array}$ & $\begin{array}{l}\text { 2-aя } \\
\text { 2-nd }\end{array}$ & $\begin{array}{l}1-\mathrm{ag} \\
1-\mathrm{st}\end{array}$ & $\begin{array}{l}\text { 2-aя } \\
\text { 2-nd }\end{array}$ & $\begin{array}{l}\text { 2-aя } \\
\text { 2-nd }\end{array}$ & \begin{tabular}{|c|} 
до \\
сшивки \\
\end{tabular} & $\begin{array}{l}\text { 2-aя } \\
\text { 2-nd }\end{array}$ & $\begin{array}{c}\text { before } \\
\text { crosslinking }\end{array}$ & $\begin{array}{ll}1-\mathrm{ar} \\
1-\mathrm{st}\end{array}$ & $\begin{array}{l}\text { 2-aя } \\
\text { 2-nd }\end{array}$ \\
\hline $\begin{array}{l}\text { 1.ПТР, г/10 мин, } 190^{\circ} \mathrm{C} \text {, нагрузка } \\
\text { 1. The MFR, g } 10 \mathrm{~min}, 190^{\circ} \mathrm{C} \text { load } \\
-5 \text { кгс kg } \\
-21 \text { кгс kgf }\end{array}$ & $>100$ & $\begin{array}{c}1,9 \\
38,6\end{array}$ & $\begin{array}{c}1,8 \\
29,3\end{array}$ & $\begin{array}{r}13,6 \\
>100\end{array}$ & $\begin{array}{c}2,2 \\
43,3\end{array}$ & $\begin{array}{c}2,0 \\
>100\end{array}$ & $\begin{array}{c}0,6 \\
16,7\end{array}$ & $\begin{array}{c}0,4 \\
10,0\end{array}$ & $\begin{array}{c}0,4 \\
12,8\end{array}$ \\
\hline 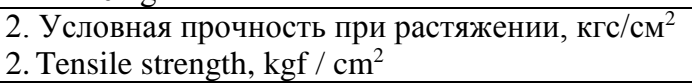 & 32 & 282 & 303 & 267 & 172 & 170 & 179 & 174 & 218 \\
\hline $\begin{array}{l}\text { 3. Относительное удлинение при разрыве,\% } \\
\text { 3. Elongation at break,\% }\end{array}$ & 810 & 1020 & 993 & 840 & 1045 & 1020 & 920 & 1020 & 963 \\
\hline $\begin{array}{l}\text { 4. Относительная остаточная деформация,\% } \\
\text { 4. Relative residual deformation,\% }\end{array}$ & 20 & 21 & 40 & 28 & 52 & 40 & 36 & 50 & 40 \\
\hline $\begin{array}{l}\text { 5. Эластичность,\% } \\
\text { 5. Elasticity,\% }\end{array}$ & 41 & - & 48 & 43 & 45 & 48 & 50 & 50 & 48 \\
\hline $\begin{array}{l}\text { 6. Твёрдость, усл. ед. } \\
\text { 6. Hardness, standard units }\end{array}$ & 26 & - & 65 & 59 & 65 & 57 & 60 & 67 & 64 \\
\hline
\end{tabular}

Низкомолекулярный полимер (оп. № 4) с характеристической вязкостью 0,57 дл/г и высокой текучестью не обладает прочностью и может быть использован в смеси с высокомолекулярными полимерами для корректировки ПТР (показатель текучести расплава).
Как показывают экспериментальные данные процесс «сшивки» двублочника в основном завершается на 1-ой стадии (снижается текучесть, повышается прочность). Вторая «сшивка» в ряде случаев, ещё более повышала прочность и, вероятно, ускоряла релаксационные процессы в полимере. 
Необходимо отметить, что в опытах № 7 и 9 пробы ДМСТ-Р до «сшивки» и после 1-ой «сшивки» имелись сопоставимые значения

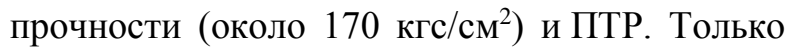
после 2-ой «сшивки» значение прочности превысило 210 кгс/см².

В ряде синтезов использовали вместо ТГФ другой электронодонор - метилтретбутиловый эфир (МТБЭ). Дозировка МТБЭ была увеличена в 2-3 раза с целью обеспечения высокой скорости полимеризации $\alpha$-метилстирола. При этом мольное соотношение МТБЭ: н-BuLi $=2,3-4,0$, тогда как в случае использования ТГФ более высокая скорость полимеризации достигается при существенно пониженном мольном соотношении ТГФ: н-BuLi $=1,5-1,7$.

При синтезе 1-го блока 70\%-я конверсия $\alpha$-метилстирола достигалась за 4 часа, молекулярная масса соответствовала дозировке н-BuLi. Синтез 2-го блока протекал активно с повышением температуры в адиабатическом режиме $(28-87)^{\circ} \mathrm{C}$.

«Сшивку» проводили в две стадии. Эффективность «сшивки» оценивали по характеристической вязкости полимера до и после «сшивки». Значение характеристической вязкости полимера после «сшивки» увеличилось в 1,4 раза.

В таблице 2 приведены физико-механические показатели образцов ДМСТ-Р, синтезированных на инициирующей системе МТБЭ н-BuLi. Как показывают данные таблицы 2, двублочный сополимер до «сшивки» обладал высокой текучестью и практически не имел прочности. В результате «сшивки» двублочника образующийся трёхблочный разветвлённый ТЭП ДМСТ-Р имел высокую прочность бо-

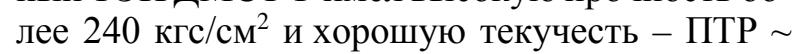
4-7 г./10 мин $\left(\mathrm{T}=190^{\circ} \mathrm{C}\right.$, нагрузка 5 кгс), что свидетельствует о высокой эффективности «сшивки» в условиях выбранного режима.

Таблица 2

Физико-механические свойства образцов ДМСТ-Р

Table 2

The physico-mechanical properties of the DMST samples

\begin{tabular}{|c|c|c|c|c|c|c|}
\hline $\begin{array}{c}\text { Наименование показателей } \\
\text { Name of indicators }\end{array}$ & \multicolumn{6}{|c|}{$\begin{array}{l}\text { Значение показателей } \\
\text { Value indicators }\end{array}$} \\
\hline $\begin{array}{c}\text { № опыта } \\
\text { experience number }\end{array}$ & \multicolumn{2}{|l|}{1} & \multicolumn{3}{|c|}{3} & \multirow{2}{*}{$\begin{array}{c}1+3 \\
\text { усредн } \\
\text { average }\end{array}$} \\
\hline $\begin{array}{c}\text { «сшивка» } \\
\text { “crosslinking” }\end{array}$ & $\begin{array}{c}\text { before } \\
\text { crosslinking }\end{array}$ & $\begin{array}{l}2 \text { 2-ag } \\
2-n d\end{array}$ & $\begin{array}{c}\text { before } \\
\text { crosslinking }\end{array}$ & $\begin{array}{l}1 \text {-aя } \\
1-\mathrm{st}\end{array}$ & $\begin{array}{l}2 \text { 2-aя } \\
\text { 2-nd }\end{array}$ & \\
\hline $\begin{array}{l}\text { 1. ПТР, г/10 мин. } 190^{\circ} \mathrm{C} \text {, нагрузка } \\
\text { 1. The MFR, g/ } 10 \mathrm{~min}, 190{ }^{\circ} \mathrm{C} \text { load } \\
-5 \text { кгс kg } \\
-21,6 \text { кгс kgf }\end{array}$ & $\begin{array}{r}36,1 \\
>100\end{array}$ & $\begin{array}{l}7,6 \\
51\end{array}$ & $\begin{array}{c}34 \\
>100\end{array}$ & $\begin{array}{l}5,5 \\
50\end{array}$ & $\begin{array}{l}4,2 \\
43\end{array}$ & $\begin{array}{l}4,6 \\
43\end{array}$ \\
\hline 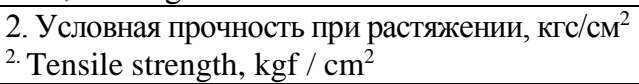 & 22 & 244 & 10 & & 208 & 245 \\
\hline $\begin{array}{l}\text { 3. Относительное удлинение при разрыве,\% } \\
\text { 3. Elongation at break,\% }\end{array}$ & 1042 & 972 & 110 & & 1020 & 967 \\
\hline $\begin{array}{l}\text { 4. Относительная остаточная деформация,\% } \\
\text { 4. Relative residual deformation,\% }\end{array}$ & 116 & 34 & 36 & & 42 & 38 \\
\hline $\begin{array}{l}\text { 5. Эластичность, \% } \\
\text { 5. Elasticity,\% }\end{array}$ & 33 & 45 & - & & 48 & 53 \\
\hline $\begin{array}{l}\text { 6. Твёрдость, усл. ед. } \\
\text { 6. Hardness, standard units }\end{array}$ & 30 & 55 & - & & 56 & 48 \\
\hline $\begin{array}{l}\text { 7. Связанный } \alpha \text {-метилстирол, } \% \\
\text { 7. Bound } \alpha \text {-methylstyrene, } \%\end{array}$ & 36 & 36 & 36 & & 36 & 36 \\
\hline $\begin{array}{l}\text { 8. Характеристическая вязкость, дл/Г } \\
\text { 8. Intrinsic viscosity, } \mathrm{dl} / \mathrm{g}\end{array}$ & 0,45 & 0,64 & 0,56 & & 0,72 & 0,73 \\
\hline
\end{tabular}

\section{Заключение}

Показано, что при синтезе опытных образцов ДМСТ-Р по духаппаратной технологической схеме с использованием каталитических систем как н-BuLi/TГФ или н-BuLi/MTБЭ, в обоих случаях достигаются заданные свойства ДМСТ-Р, соответствующие ТУ 38103585-85.
Установлено, что тетраэтоксисилан, выбранный в качестве «сшивающего» агента обеспечивает высокую эффективность «сшивки».

Оптимальный состав растворителя при этом должен соответствовать соотношению циклогексан: нефрас $=(80-70):(20-30) \%$ масс. 


\section{ЛИТЕРАТУРА}

1 Пат. № W02014142637 (A1), KZ, C08K13/04, C08L23/06. Способ получения термоэластопластов / Иманов А., Мухтар С., Сарсенбаева А., Нуркенов Н., Искужин А. № WO2013KZ00003 20130314; Заявл. 14.03.2013; Опубл. 18.09.2014.

2 De Rosa C., Auriemma F. Single site metalorganic polymerization catalysis as a method to probe the properties of polyolefins // Polymer chemistry. 2011. V. 2. № 10. P. 2155-2168. DOI: 10.1039/c1py00129a

3 Ахметов И.Г. и др. Кинетика полимеризации и молекулярные характеристики литиевого полибутадиена: влияние концентрации толуола и гексена-1 // Каучук и резина. 2010. № 3. C. $2-4$.

4 Ахунова Р.Р. и др. Модифицирующая добавка для дорожного битума // Электронный научный журнал нефтегазовое дело. 2013. № 2. C. 359-369.

5 Подкопаева С.В., Хромых Ё.А. Обоснование выбора технологического режима синтеза дивинил-стирольных термоэластопластов // Промышленное производство и использование эластомеров. 2014. № 2. С. 28-30.

\section{СВЕДЕНИЯ ОБ АВТОРАХ}

Алена В. Фирсова аспирант, кафедра химии и химической технологии органических соединений и переработки полимеров, Воронеж, гос. ун-т. инж. техн., Ленинский пр-т, 14, г. Воронеж, Россия, vammp.004@mail.ru

Ольга В. Карманова д.т.н., профессор, кафедра химии и химической технологии органических соединений и переработки полимеров, Воронеж. гос. ун-т. инж. техн., Ленинский пр-т, 14, г. Воронеж, Россия, karolga@mail.ru

Валентина В. Ситникова к.Х.н., старший научный сотрудник, Воронежский филиал НИИСК, ул. Менделеева, 3Б, г. Воронеж, 394014, Россия, vfniisk2007@yandex.ru

Евгений В. Блинов директор, Воронежский филиал НИИСК, ул. Менделеева, ЗБ, г. Воронеж, 394014, Россия, vfniisk2007@yandex.ru

\section{КРИТЕРИЙ АВТОРСТВА}

Алена В. Фирсова обзор литературных источников по исследуемой проблеме, провел эксперимент, выполнил расчеты Ольга В. Карманова консультация в ходе исследования Валентина В. Ситникова предложил методику проведения эксперимента и организовал производственные испытания Евгений В. Блинов написал рукопись, корректировал её до подачи в редакцию и несет ответственность за плагиат

\section{КОНФЛИКТ ИНТЕРЕСОВ}

Авторы заявляют об отсутствии конфликта интересов.

ПОСТУПИЛА 28.03.2016

ПРИНЯТА В ПЕЧАТЬ 26.04.2016

\section{REFERENCES}

1 Imanov A., Mukhtar S., Sarsenbaeva A., Nurkenov N. et al. Sposob polucheniya termoelastoplastov [Method for producing thermoplastic elastomers] Patent KZ, no. WO/2014/142637, 2014. (in Russian)

2 De Rosa C., Auriemma F. Single site metalorganic polymerization catalysis as a method to probe the properties of polyolefins. Polymer chemistry, 2011, vol. 2, no. 10, pp. 2155-2168. DOI: 10.1039/c1py00129a

3 Akhmetov I.G., Boreyko N.P., Bourganov R.T., GluchovskoiV.S. et al. Kinetic parameters of "lithium" polybutadiene polymerization and its molecular characteristics - the influence of toluene and hexane-1 concentration. Kauchuk I rezina. [Rubber], 2010, no. 3, pp.2-4. (in Russian).

4 Akhunova R.R., Biglova R.Z., Talipov R.F., Tsadkin M.A. et al. A modifying additive to road bitumen. Elektronnyi nauchnyi zhurnal neftegazovoe delo. [Electronic science journal of the oil and gas business], 2013, no. 2, pp. 359-369. (in Russian).

5 Podkopaeva S.V., Khromykh E.A. Justification of the choice of the technological mode of production of butadiene-styrene thermoplastic elastomer. Promyshlennoe proizvodstvo i is-pol'zovanie elastomerov. [Indusrtrial production and use of elastomers], 2014, no. 2, pp. 28-30. (in Russian)

\section{INFORMATION ABOUT AUTHORS}

Alena V. Firsova graduate student, chemistry and chemical technology of organic compounds and polymer processing department, Voronezh state university of engineering technologies, Leninsky Av., 14 Voronezh, Russia, vammp.004@mail.ru

Olga V. Karmanova D. t. sc., professor, chemistry and chemical technology of organic compounds and polymer processing department, Voronezh state university of engineering technologies, Leninsky Av., 14 Voronezh, Russia, karolga@mail.ru

Valentina V. Sitnikova Ph. D., senior researcher, Voronezh branch NIISK, Mendeleev street, 3B Voronezh, 394014, Russia, vfniisk2007@yandex.ru

Evgeniy V. Blinov director, Voronezh branch NIISK, Mendeleev street, 3B Voronezh, 394014, Russia, vfniisk2007@yandex.ru

\section{CONTRIBUTION}

AlenaV. Firsova review of the literature on an investigated problem, conducted an experiment, performed computations OlgaV. Karmanova consultation during the study

Valentina V. Sitnikova proposed a scheme of the experiment and organized production trials

Evgeniy V. Blinov wrote the manuscript, correct it before filing in editing and is responsible for plagiarism

\section{CONFLICT OF INTEREST}

The authors declare no conflict of interest.

RECEIVED 3.28.2016

ACCEPTED 4.26.2016 